\title{
\&ditorial
}

\section{Formación Continuada}

Formación Continuada, Formación Permanente, Formación Obligatoria o Formación Voluntaria

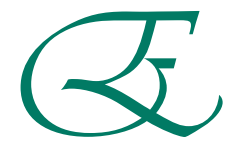

stamos en una sociedad que evolucio-

na permanentemente y a gran velocidad, pudiéndose dar la circunstancia de que una técnica que hoy nos parece correcta al cabo de poco meses ha podido quedar obsoleta.

Nuestra profesión de dentistas es una profesión rica, tanto en avances técnicos como de materiales, que nos obliga a una actualización permanente, para conseguir que la sociedad reciba de nosotros el mejor tratamiento ante cada caso que se nos presente.

Es evidente, que en ninguna profesión, y menos en la nuestra, directamente relacionada con la salud, se puede vivir con los únicos conocimientos adquiridos durante la Licenciatura.

¿Te gustaría ser tratado por un profesional que no se reciclase nunca? No, iverdad?, pues a tus pacientes tampoco.

creo que todos estamos de acuerdo con lo anterior, por lo tanto está claro que la formación continuada debería ser obligatoria.

Si hemos llegado a esta conclusión, nos preguntamos ¿cuántas horas al año serían necesarias? Los miembros de la Comisión de Formación Continuada del Consejo General, consideramos que entre 16 a 20 horas anuales, lo representan, aproximadamente, dos cursos de los que se vienen impartiendo.

El Consejo General siempre ha creído en una Formación Continuada obligatoria y reglada, por ello, y mientras los organismos competentes lo establecen, creó hace bastantes años una Comisión encargada de promover una Formación Continuada seria y eficaz, con garantía de calidad.

Para ello, desde sus inicios ha contado con un destacado cuadro de profesores que engloban todas las materias, y que, desinteresadamente, acuden a cualquier rincón de nuestra geografía donde son requeridos para impartir sus conocimientos.

Actualmente, el Programa de Formación continuada del Consejo General cuenta con más de 100 cursos que cubren todas las temáticas.

También desde el año 1997, se está llevando cabo un Aula Clínica de Educación Continuada Permanente, con la que se pretende en cada edición una puesta al día en una materia diferente.

Uno de nuestros mayores logros es el haber conseguido que el mejor de los mejores dictantes acuda a cualquier rincón de España.

Todos los años más de 4000 asistentes, un número importante pero no suficiente, se benefician de estos cursos del Consejo General, patrocinados por la Fundación Dental Española.

Los miembros de la Comisión nos sentimos con la responsabilidad de continuar trabajando para seguir mejorando, para llegar a mas sitios y con mejores cursos.

Queremos ser la competencia de la multitud de cursos que han surgido últimamente en nuestra profesión, algunos buenos pero la mayoría con afán de lucro como fin, aprovechándose de la necesidad de formación de nuestros colegiados.

Pero tenemos que contar contigo, con tu asistencia y tu crítica constructiva, por lo que te animamos para que nos las hagas llegar. También te animamos para que si, estás interesado en colaborar como dictante de cursos, nos remitas (ateniéndote a las condiciones establecidas) los datos que te solicitamos.

Contamos contigo para esta labor que es tan necesaria y beneficiosa para nuestra querida profesión.

Fernando Sabras Puras Presidente de la Comisión de Formación Continuada del Consejo General 